\title{
Paródias no ensino de microbiologia: a música como ferramenta pedagógica
}

\section{Parodies in the teaching of microbiology: music as a pedagogical tool \\ Parodias en la enseñanza de la microbiología: la música como herramienta pegagógica}

Germana Costa Paixão |germana.paixao@uece.br

Universidade Estadual do Ceará, Curso de Ciências Biológicas a distância. Fortaleza, Brasil.

Liliane Araújo Lima | liliane.lima@uece.br

Universidade Estadual do Ceará, Curso de Ciências Biológicas a distância. Fortaleza, Brasil.

Nayana de Jesus Oliveira Colaço | nayana.colaco@gmail.com

Universidade Estadual do Ceará, Curso de Ciências Biológicas a distância. Fortaleza, Brasil.

Raenia AlmeidaLima | raeniaameida@gmail.com

Universidade Estadual do Ceará, Curso de Ciências Biológicas a distância. Fortaleza, Brasil.

Tamyres Carvalho Casimiro | tamyrescarvalho@hotmail.com

Universidade Estadual do Ceará, Curso de Ciências Biológicas a distância. Fortaleza, Brasil.

Laura Helena Pinto Castro | laura.castro@uece.br

Universidade Estadual do Ceará, Curso de Ciências Biológicas a distância. Fortaleza, Brasil.

Lydia Dayanne Maia Pantoja | lydia.pantoja@uece.br

Universidade Estadual do Ceará, Curso de Ciências Biológicas a distância. Fortaleza, Brasil.

\section{Resumo}

Atividades lúdicas, como as paródias, são estratégias didáticas motivadoras para a aprendizagem e configuram-se como forma criativa e crítica de trabalhar o aprendizado. O presente artigo objetiva descrever o processo de construção e divulgação de paródias como instrumento facilitador para transmissão e assimilação de conteúdos microbianos, no âmbito do projeto de extensão 'Musicalizando a Biologia', vinculado ao Curso de Ciências Biológicas a distância da Universidade Estadual do Ceará/ Universidade Aberta do Brasil. Trata-se de relato de experiência da produção de três paródias na qual foi possível estabelecer os critérios e os conteúdos, bem como a escolha de músicas populares que viriam a facilitar a fixação da melodia e da letra contendo as ideias que se queria transmitir. Os resultados indicam que a utilização dessa ferramenta pode oferecer contribuições significativas para o ensino e favorecer a aprendizagem dos conteúdos em microbiologia.

Palavras-chave: bactérias; paródias; ensino de microbiologia; aprendizagem; criatividade. 


\begin{abstract}
Fun activities, such as parodies, are among the creative teaching strategies that can motivate learning and critical analysis. This article describes the process of constructing and diffusion of parodies as an instrument for transmission and assimilation of the technical concepts involving microbiology, in the project called 'Musicalizando a Biologia' (musicalization of biology), associated with the distance education undergraduate course in biology offered by University of Ceará/Open University of Brazil. It is a experience report of the production of three parodies, through which it was possible to establish the criteria, as well as the choice of popular melodies to facilitate memorization of the content and ideas. The results indicate that the use of this tool can make significant contributions to teaching and favoring the learning of concepts of microbiology.
\end{abstract}

Keywords: bacteria; parodies; teaching of microbiology; learning; creativity.

\title{
Resumen
}

Actividades lúdicas, como parodias, son estrategias de enseñanza motivadoras y se configuran como forma creativa y crítica para trabajar el aprendizaje. Este artículo describe el proceso de construcción y divulgación de parodias como facilitador para la transmisión y asimilación de contenido microbiano dentro del proyecto denominado 'Musicalizando a Biologia', vinculado a el curso de ciencias biológicas a distancia de la Universidad del Estado de Ceará/Universidad Abierta de Brasil. Se trata de un relato de experiencia de la producción de tres parodias, por la cual fue posible establecer los criterios y contenidos, así como la elección de canciones populares que facilitasen la memorización de la melodía y de la letra con las ideas que se quería transmitir. Los resultados indican que el uso de esta herramienta puede ofrecer contribuciones significativas a la enseñanza y favorecer el aprendizaje de contenidos en microbiología.

Palabras clave: bacterias; parodias; enseñanza de microbiología; aprendizaje; creatividad.

Declaração de conflito de interesses: Não há conflito de interesses;

Fontes de financiamento: Universidade Estadual do Ceará e Universidade Aberta do Brasil.

Agradecimento/Contribuições adicionais: Ao Centro Vocacional Tecnológico Rui Facó/Beberibe-Ceará;

Histórico do artigo: Submetido: 29.jan.2016 | Aceito: 16.jan.2017 | Publicado: 31.mar.2017

Apresentação anterior: não houve.

Licença CC BY-NC atribuição não comercial. Com essa licença é permitido acessar, baixar (download), copiar, imprimir, compartilhar, reutilizar e distribuir os artigos, desde que para uso não comercial e com a citação da fonte, conferindo os devidos créditos de autoria e menção à Reciis. Nesses casos, nenhuma permissão é necessária por parte dos autores ou dos editores. 


\section{Introdução}

O segredo do bom ensino é o entusiasmo pessoal do professor, que vem de seu amor à ciência e aos alunos ${ }^{1}$. Para tanto, se faz necessário um bom planejamento e o uso de metodologias de ensino adequadas, sendo mais importante o professor acompanhar a aprendizagem do aluno do que se concentrar demasiadamente no conteúdo a ser ensinado². Assim, com a expansão do acesso à educação superior, amplifica-se a demanda por professores capacitados, meios didáticos inovadores e suporte com material de qualidade, para finalmente concretizar-se a nova realidade educacional ${ }^{3}$.

O ensino e a aprendizagem da biologia apresentam desafios a serem superados pelos professores, que buscam, a cada dia, novas estratégias que possam auxiliá-los nesse processo. As principais dificuldades estão relacionadas às questões didático-pedagógicas, à natureza abstrata de alguns conteúdos e à influência de concepções alternativas como barreiras para a aprendizagem ${ }^{4}$.

Dessa forma, é eminente a necessidade do desenvolvimento de diferentes competências relacionadas ao processo ensino-aprendizagem, o que implica em exercício de reflexão que permita ao facilitador criar e renovar ferramentas educacionais, sempre com vistas a resolver eventuais dificuldades relacionadas à apreensão do conhecimento ${ }^{5}$.

Em se tratando da microbiologia, alguns autores ${ }^{6}$ revelam que, apesar de sua grande relevância, essa disciplina "é muitas vezes negligenciada pelos professores, provavelmente devido às dificuldades para o desenvolvimento de estratégias pedagógicas mais dinâmicas e atraentes para os estudantes”.

A microbiologia é a ciência que estuda bactérias, fungos e vírus, abordando aspectos harmônicos e desarmônicos, resultantes da interação desses organismos entre si e com os demais seres vivos. Essa ciência deixou, há muito, de ser assunto restrito a laboratórios para ser tema relacionado a questões básicas de cidadania, envolvendo o meio ambiente, o cotidiano, a higiene, enfim, o ser humano e o meio em que ele vive, em especial, através dos diversos meios de interação e comunicação. Hoje, frente ao intenso desenvolvimento das tecnologias digitais e das redes sociais de comunicação, há inúmeras possibilidades de ampliação da interatividade através do uso do Facebook $\AA$, de sites como o YouTube $®$ e de diversos softwares, tornando-se essencial que o conhecimento sobre essa área ultrapasse as barreiras do tecnicismo e seja acessível em todos os níveis educacionais.

O conhecimento sobre conteúdos microbianos auxilia os alunos a descobrirem a influência desses microorganismos em suas vidas, bem como as funções essenciais que eles desempenham no corpo humano e no ambiente ${ }^{7}$. Nesse contexto, uma das principais dificuldades do aprendizado é justamente a falta de conexão entre conteúdos específicos e o cotidiano e, por isso, faz-se necessário o desenvolvimento de estratégias e tecnologias que estimulem os estudantes para o conhecimento dos micro-organismos e sua relação com a vida cotidiana, despertando o aluno para a conscientização da aplicabilidade dessa ciência no dia a dia ${ }^{8}$. Portanto, as atividades lúdicas se configuram como excelentes recursos que favorecem essa conexão e promovem uma ampliação do ensino da microbiologia9.

Logo, a inserção de elementos lúdicos em cursos de formação de professores em diferentes áreas, como biologia $^{10}$, geografia ${ }^{11}$, química ${ }^{12}$, entre outras, representa um mecanismo eficiente para amplificar o processo de ensino-aprendizagem, sendo elemento facilitador de transmissão de conhecimento, fato corroborado, quando se afirma que o lúdico pode ser utilizado como promotor da aprendizagem nas práticas docentes, pois, possibilita a aproximação do conhecimento científico pelos alunos ${ }^{10}$. Além disso, considera-se a paródia como "um exercício interessante para demonstrar, representar e aplicar os conteúdos teóricos, constituindo uma forma criativa e crítica de encarar o aprendizado de forma prática" ${ }^{11}$.

A utilização de ferramentas pedagógicas alternativas como as atividades lúdicas pode auxiliar e despertar o interesse dos alunos, podendo ser aplicadas em todos os níveis de ensino ${ }^{13}$. Logo, a ludicidade "é abordada como um processo social, em que o brincar não é uma atividade interna do indivíduo pura e simplesmente, 
mas dotada de uma significação social precisa que facilite o processo de aprendizagem entre os participantes inseridos em um ambiente interativo"13.

Assim, as atividades lúdicas se apresentam como estratégias didáticas motivadoras para a aprendizagem, pois quando bem trabalhadas, podem não apenas facilitar a aprendizagem, mas também o desenvolvimento pessoal, social e cultural, e consequentemente a comunicação, expressão e construção do conhecimento ${ }^{14}$.

Dentre as várias ferramentas metodológicas lúdicas que vêm sendo aplicadas em sala de aula, destacamos a música, que vem desempenhando, ao longo da história, importante papel no desenvolvimento do ser humano, seja no aspecto religioso, moral ou social, contribuindo para a formação de valores indispensáveis ao exercício da cidadania ${ }^{15}$. Além disso, estreita laços entre os alunos, professores e a ciência de forma significativa, sendo capaz de motivar e estimular o aluno, facilitando a aprendizagem e desenvolvendo a socialização do indivíduo ${ }^{16}$.

A música requer uma "proposta curricular que considere as diferenças culturais, o respeito à individualidade e às experiências de cada aluno e, principalmente, as vivências musicais que os mesmos levam para dentro do espaço escolar" ${ }^{15}$. Assim, a letra da música elaborada por um aluno configura-se como uma ferramenta rica e inovadora que permite estimular a linguagem cognitiva e a intertextualidade; tratase da influência de um texto sobre outro que o toma como modelo ou ponto de partida e, por esse fato, deve ser explorada a fim de diversificar e contextualizar a aprendizagem ${ }^{16}$.

Nesse sentido, a utilização de paródias ${ }^{11}$ "é um exercício interessante para demonstrar, representar e aplicar os conteúdos teóricos, constituindo uma forma criativa e crítica de encarar o aprendizado de forma prática”. Portanto, deve ser dada atenção ao fato de que utilizar paródias não deve ser uma atividade de simples memorização, uma vez que esse recurso traz a possibilidade de situar a música na realidade dos estudantes, permitindo inclusive que essa realidade seja problematizada e contextualizada ${ }^{12}$.

Diante desse contexto, o presente artigo objetiva descrever o processo de construção e divulgação de paródias como instrumentos facilitadores para transmissão e assimilação de conteúdos microbianos, no âmbito do projeto de extensão "Musicalizando a Biologia", coordenado pelo Curso de Ciências Biológicas a distância da Universidade Estadual do Ceará/Universidade Aberta do Brasil - UECE/UAB (BIOEaD). Ao se dedicar à produção de paródias, esse projeto aborda temáticas relacionadas a diversos conteúdos de disciplinas do curso, buscando contribuir para os processos de ensino e aprendizagem da biologia.

\section{Metodologia}

Trata-se de um relato de experiência, de abordagem qualitativa descritiva exploratória, do processo de construção e divulgação de paródias como instrumento facilitador para transmissão e assimilação de conteúdos microbianos, elaboradas pelos membros do projeto de extensão mencionado no parágrafo anterior.

Foram elaboradas três paródias e para tal o grupo se reuniu semanalmente, num período de seis meses, a fim de estabelecer os critérios e definir os conteúdos que seriam abordados. A escolha das canções a serem parodiadas, baseou-se no nível de popularidade no mercado fonográfico nacional, pois acreditou-se que isso facilitaria a fixação da melodia e, consequentemente, da letra com as ideias que se queria transmitir.

No processo de montagem e edição, as paródias foram produzidas apenas em áudio e foram utilizados fragmentos de imagens de vários vídeos da rede (YouTube $($ ) que condiziam com o conteúdo dos trabalhos, sendo todo esse material devidamente referenciado. Por meio do software Movie Make $\AA$ da Microsoft $\AA$, as edições foram realizadas fazendo junção do áudio e dos vídeos produzidos que receberam os efeitos, cortes e ajustes necessários.

A forma como as paródias foram divulgadas representa uma estratégia importante para a potencialização do uso dessa ferramenta pedagógica visto que, além de serem utilizadas durante as aulas do curso, como forma de auxiliar os alunos na compreensão dos conteúdos de microbiologia, também foram publicadas na forma de vídeos musicais, contendo animações e esquemas, em um canal específico no YouTubeß, para 
serem acessadas pela comunidade estudantil como um todo. Outra forma de divulgação foi por meio do blogue i do grupo Musicalizando a Biologia.

As paródias foram também postadas em um grupo específico do curso em questão, na rede social Facebook $囚$, com acesso restrito aos alunos, professores, tutores e coordenadores, o que proporciona canal para divulgação, permitindo discussões sobre as temáticas abordadas nessas paródias, análises críticas e reflexões importantes que podem favorecer a aprendizagem.

Por fim, essas paródias vêm sendo também trabalhadas didaticamente em feiras de ciências, escolas e eventos na área da educação, que ocorrem nos municípios de abrangência do polo de apoio presencial de Beberibe/Ce.

\section{Resultados e discussão}

As três paródias produzidas pelo grupo versaram sobre resistência bacteriana, estrutura da bactéria e prevenção da dengue.

Na paródia intitulada 'Resistência bacteriana', elaborada a partir da música interpretada por Luan Santana, "Tudo que você quiser", buscou-se explorar os mecanismos de resistência das bactérias aos antimicrobianos, alertando sobre os riscos do uso negligente de medicamentos.

Música: Tudo que você quiser / Intérprete: Luan Santana.

Paródia: Resistência bacteriana ${ }^{\text {ii }}$

Produção: Equipe Musicalizando a biologia.

Tem dias que eu acordo tentando entender

O que uma bactéria faz pra se multiplicar

É tanta resistência para um só ser

Transformações genéticas pra se modificar.

Trocam seus plasmídeos para serem resistentes

Sofrem mutações e formam novos genes

Invadem tudo, sobrevivem muito.

E os antimicrobianos têm um alvo a alcançar

Precisam ultrapassar a sua membrana celular

A bactéria inteira, ele vai destruir.

A reação da bactéria é limitar

A permeabilidade da membrana celular

Codificam um novo gene no sítio de ação

E resistem ao produto com essa alteração

E ainda usam suas enzimas

Para tentar destruir os antimicrobianos

Com o passar dos anos nós estamos percebendo

Que essas bactérias estão se fortalecendo

E isso é grave, preocupa muito.

Por isso não se deve usar grandes quantidades

Dos antimicrobianos pois perdem sua qualidade

$\mathrm{E}$ a bactéria não pode evoluir.

Disponível em http://musicalizandoabiologia.blogspot.com.br

ii Paródia 'Resistência bacteriana', produzida pelo grupo musicalizando a biologia, durante a disciplina de microbiologia da turma 2012 polo de Beberibe, curso de Licenciatura em Ciências Biológicas a distância UAB/UECE. Disponível em: https://youtu.be/f3zoHUmtDCE 
A paródia fez parte de uma das atividades da disciplina Microbiologia, e o principal resultado desse trabalho não foi apenas a paródia em si, mas como ocorreu seu processo de elaboração, tendo em vista que ela foi construída e reconstruída (havendo inúmeras tentativas de encaixe entre conteúdo científico e ritmo da música original), de forma que os conceitos de microbiologia trabalhados puderam ser aprofundados através de pesquisas mais detalhadas em fontes diversas, reanalisados e refeitos quando necessários.

Dessa forma, o uso de paródias como estratégia de ensino e aprendizagem pode ser justificado pelo fato de que elas não somente despertam o interesse de autoria e elaboração de um "novo produto", como também de forma lúdica induzem o aluno a buscar mais informações que possam se adequar à música a ser parodiada e também a relacionar critérios preestabelecidos pelo professor ${ }^{10}$.

Além disso, ao se observar o conteúdo abordado sobre resistência bacteriana, no trecho da paródia "É tanta resistência para um só ser / transformações genéticas pra se modificar / trocam seus plasmídeos para serem resistentes / sofrem mutações e formam novos genes / invadem tudo, sobrevivem muito / e os antimicrobianos têm um alvo a alcançar / precisam ultrapassar a sua membrana celular", percebese que é dada ênfase ao fato de as bactérias utilizarem mais de uma estratégia para evitar a ação dos antimicrobianos, revelando que a ação conjunta de múltiplos mecanismos pode produzir um acentuado aumento da resistência dessas bactérias, conforme destacado no seguinte trecho: "A reação da bactéria é limitar / a permeabilidade da membrana celular / codificam um novo gene no sítio de ação / e resistem ao produto com essa alteração / e ainda usam suas enzimas / para tentar destruir os antimicrobianos”. Assim, tais conteúdos podem ser mais facilmente assimilados pelo aluno dando-lhe condições de entender melhor sobre como ocorre o processo de resistência bacteriana aos antimicrobianos, ao se enfatizar a importância dos seus mecanismos de ação bem como as propriedades necessárias para a sua eficácia.

A paródia da música "Humilde residência”, do cantor Michel Teló e intitulada 'Humilde consciência' iii, foi produzida para uma ação de intervenção de educação em saúde colaborativa em uma campanha contra a dengue e idealizada para duas escolas públicas de Sucatinga, distrito de Beberibe-CE, da qual o grupo participou como convidado de ações extensionistas. Foi realizada uma palestra de conscientização para os alunos em que foram expostos conhecimentos sobre o ciclo de vida do mosquito Aedes aegypti, os riscos da doença e as principais formas de prevenção, com o auxílio de slides, vídeos e fotografias, culminando com a apresentação da paródia que, como dito anteriormente, é uma forma lúdica e divertida de apresentar conteúdos de biologia.

Música: Humilde residência / Intérprete: Michel Teló.

Paródia: Humilde consciência

Produção: Equipe Musicalizando a biologia.

Você vê um foco aqui,

O pneu tá descoberto, a garrafa destampada,

O mosquito vai surgir.

Porque a água tá parada ela não pode escoar

$\mathrm{E}$, quando o sol surgir,

Vai ser tudo de repente, uns dois dias vai levar

Pro ovo eclodir,

E as larvas vão ficar ativas.

iii Paródia 'Humilde consciência', produzida pelo grupo musicalizando a biologia, durante campanha contra a dengue, realizada por duas escolas públicas de Sucatinga, distrito de Beberibe-CE. Disponível em: https://youtu.be/NUT4TpAFI-A 
Já te falei o passo a passo do processo

Como você se prevenir na sua casa

Cê tá ligado que é só não dá moral

para o mosquito achar uma água parada

Agora se você tomar esses cuidados

Mas os vizinhos não fizerem a sua parte

Eles atrás, você na frente,

sem a ajuda dessa gente a dengue vai te pegar

Não vá esperar

Para combater a dengue, e o foco eliminar

E eu te peço

Só um pouquinho de consciência,

o mosquito tá ganhando não vamos deixar.

Na paródia, foram abordadas as principais formas de proliferação do mosquito transmissor da dengue, como mostra o trecho "Você vê um foco aqui / o pneu tá descoberto, a garrafa destampada / o mosquito vai surgir / porque a água tá parada ela não pode escoar / e, quando o sol surgir / vai ser tudo de repente, uns dois dias vai levar / pro ovo eclodir / e as larvas vão ficar ativas".

Em outro trecho, foi dado destaque às formas de combate à dengue e de sua prevenção: "Já te falei o passo a passo do processo / como você se prevenir na sua casa / cê tá ligado que é só não dá moral / para o mosquito achar uma água parada”, bem como enfatizou-se a necessidade de uma conscientização da população sobre essa problemática: "Agora se você tomar esses cuidados / mas os vizinhos não fizerem a sua parte / eles atrás, você na frente / sem a ajuda dessa gente / a dengue vai te pegar".

Além desses aspectos sobre a dengue, a ação pretendia também sensibilizar os alunos sobre os riscos e a prevenção da doença, de forma que a comunidade escolar se sentisse mais motivada a participar de outras ações preventivas, buscando uma mudança na atitude das pessoas com a adoção de condutas saudáveis em seu ambiente.

A palestra de conscientização atingiu 360 alunos do Ensino Médio, 150 alunos do Ensino Fundamental e 70 alunos da Educação Infantil, demonstrando que ações como essa são importantes para o exercício da cidadania e destacando que a utilização de paródias representa uma excelente estratégia de ensino na promoção de um aprendizado mais significativo, como destacado por alguns autores ${ }^{14}$, quando afirmam que "o uso de paródias pode ser uma ótima estratégia didática aliada ao ensino e aprendizagem, não se delimitando apenas ao seu caráter divertido e prazeroso".

Por último, foi elaborada uma paródia intitulada 'Célula bacteriana'iviv, a partir da música "Vou deixar" do grupo Skank, em que se buscou evidenciar a estrutura da célula bacteriana, seus constituintes, formas e arranjos. A presente abordagem destaca o conteúdo, explorado de forma menos abstrata e mais atraente aos alunos, e constitui uma possibilidade para se trabalhar temas previstos no currículo de ciências e biologia de maneira a subsidiar o processo de ensino e aprendizagem voltado para a alfabetização científica e a apropriação de conhecimentos relacionados ao desenvolvimento de competências e habilidades, bem como a oferecer uma alternativa lúdica.

iv Paródia 'Célula bacteriana', produzida pelo grupo musicalizando a biologia, do curso de Licenciatura em Ciências Biológicas a distância UAB/UECE. Disponível em: https://youtu.be/2jycOPJJlsl. 
Música: Vou deixar / Intérprete: Skank

Paródia: Célula bacteriana ${ }^{3}$

Produção: Equipe Musicalizando a biologia

Vou falar

Da bactéria

E toda sua estrutura

Suas formas e arranjos

Você vai saber qual é-é

Cocos, bacilos e espirilos-juntos

Formando arranjos bacterianos:

Estreptococos e sarcinas

A célula é procariótica

Uma estrutura simples

Seus componentes são:

Flagelos, fímbrias e cápsulas

Esporos, plasmídios, nucleoides

Parede e membrana celular

E o citoplasma a completar

Os flagelos são helicoidais

Tem monotríquios e anfitríquios

E quando formam tufos

Chamamos de lofotríquios

$\mathrm{E}$ as fímbrias sexuais

Pra adesão na conjugação

A cápsula

Que circunda a bactéria

É frouxamente aderida

À parede celular

Uma estrutura mais rígida

Que dá a forma à bactéria

E essencial ao crescimento

E protege a célula

Tem ainda uma bicamada

De fosfolipídios e proteínas

É a membrana celular

Onde se produz energia

$\mathrm{E}$ depois dela temos

O citoplasma da bactéria

Não não não esquecendo o nucleoide não

Molécula longa de DNA

Sem a membrana nuclear

Não não não é só o nucleoide não

Tem pedaços de DNA

Que chamamos de plasmídios 
A produção dessa paródia visou abordar temas transversais, que possam ser aplicados no Ensino Fundamental e no Médio das escolas públicas e particulares de Beberibe/Ce.

No caso do ensino de microbiologia, uma peculiaridade refere-se à necessidade de realização de atividades que permitam ao aluno a percepção de um universo totalmente novo, ou seja, o dos organismos visíveis apenas por meio do microscópio ${ }^{9}$. Segundo os autores, "essa vivência deve ser suficientemente significativa para promover mudança de hábitos e atitudes por parte daqueles que participam do processo de aprendizagem e assimilação de conteúdos relacionados à microbiologia"”.

Na elaboração da paródia, buscou-se trazer elementos que caracterizassem a célula bacteriana. Palavras tais como procariótica, plasmídios e parede celular foram utilizadas, visando contribuir para a construção do pensamento científico dos alunos. Em trechos da paródia, a definição de procariontes fica evidente, pois foram feitas abordagens morfológicas, destacando-se a estrutura bacteriana e seus componentes, tendo em vista que, quando se fala em bactérias, estas são características consideradas importantes para o grupo: "A célula é procariótica / uma estrutura simples / seus componentes são flagelos, fímbrias e cápsulas / esporos, plasmídios, nucleoides / parede e membrana celular". Assim, a utilização dessa ferramenta, pode dar contribuições significativas para o ensino e favorecer a aprendizagem dos conteúdos.

No tocante ao conteúdo geral das paródias construídas, foi constatado que os assuntos estão distribuídos nos eixos temáticos dos Parâmetros Curriculares Nacionais (PCNs) do Ensino Fundamental, principalmente em "Vida e ambiente" e "Ser humano e saúde", demonstrando a relevância desses conteúdos abordados para o conhecimento na formação dos alunos ${ }^{17}$. Cabe destacar que os Parâmetros Curriculares Nacionais para Ciências Naturais do Ensino Fundamental se apresentaram como um documento norteador fundamental, bem como a exploração de conteúdos relacionados à saúde se mostra importante em uma época em que o mundo está em um nível de globalização tão grande, que o surgimento de uma doença em determinado local pode levar à sua expansão, tomando enormes proporções e atingindo milhares de pessoas. Portanto, o conhecimento sobre a existência e importância dos micro-organismos confere grande relevância aos assuntos de ciências relacionados à microbiologia.

Por fim, no que diz respeito à escolha dos canais de divulgação, as paródias foram publicadas na forma de vídeos musicais, contendo animações e esquemas que podem, comprovadamente, ser utilizados como recursos de dinamização do fazer pedagógico, considerando a mídia uma facilitadora na compreensão do conteúdo e na construção do conhecimento, pois envolve mais de um dos sentidos do estudante, tanto no ensino presencial quanto no ensino a distância ${ }^{18-19}$. Além disso, existe um crescente repositório de mídias para ser utilizado no ensino a distância ${ }^{18}$, e a enorme quantidade de vídeos online gratuitos, combinada com inúmeras outras ferramentas, trazem novas oportunidades para integrar conteúdo multimídia em EaD.

Outro meio importante de divulgação tem sido o blogue construído para socializar as paródias produzidas pelo grupo musicalizando a biologia. A importância dos blogues educativos reside no fato de que eles permitem que os visitantes deixem suas contribuições, seja através de comentários sobre os temas abordados ou indicando outras leituras, filmes e sites afins que possam complementar o assunto abordado $^{20}$. Desta forma o blogue pressupõe coautorias, o que lhe confere maior dinamismo e interação, além de permitir atualizações constantes por parte dos autores ${ }^{21}$.

O processo de criação, montagem e designer do blogue do grupo Musicalizando a biologia foi iniciado no mês de março de 2015, e feito no Blogger $囚$, serviço escolhido por ser gratuito, mais intuitivo, fácil de usar, com layout simples que não precisa de configuração e que, além disso, fica hospedado diretamente dentro dos servidores da Google $\Re$, permitindo que ele esteja sempre online e acessível para todos. O blogue em questão, cujo endereço encontra-se na nota de rodapé i deste artigo, foi inaugurado em abril de 2015 e, atualmente, apresenta as informações gerais sobre o projeto, os objetivos a serem alcançados pelo mesmo, as paródias criadas, gravadas e disponibilizadas na internet através do YouTube®. Além disso, são também divulgados os eventos realizados pelo grupo, que incluem visitas a escolas com apresentação de 
paródias que trabalham conteúdos de ciências, levando ludicidade ao ambiente escolar e promovendo um aprendizado mais prazeroso.

Com relação à divulgação das paródias no grupo fechado da rede social Facebook®, por meio da análise dos comentários feitos pelos alunos, os resultados obtidos evidenciaram uma melhora na capacidade de análise crítica e reflexiva sobre o assunto nelas abordados. Mais uma vez, fica demonstrado que a utilização dessa ferramenta pode enriquecer os conhecimentos em relação à microbiologia, já que os conteúdos explorados nas paródias proporcionaram maior contextualização entre os micro-organismos e outras áreas do conhecimento, destacaram sua importância na natureza, bem como aprofundaram a análise de suas características biológicas.

Dessa forma, constatou-se que o uso do canal específico no YouTube $®$, bem como a divulgação das paródias na rede social Facebook® e no blogue do grupo musicalizando a biologia podem ser elementos facilitadores e mediadores do processo de aprendizagem.

Ademais, a utilização das paródias em feiras de ciências abre um leque de possibilidades pois, através do trabalho feito nas escolas, é possível associar os conteúdos de microbiologia com o cotidiano dos alunos de forma que eles passam a estabelecer uma correspondência entre os fenômenos descritos na teoria com aqueles que ocorrem no seu dia a dia, "garantindo a eficácia na aprendizagem e, por conseguinte, oportunizando uma melhor qualidade de vida pela aquisição de um conhecimento contextualizado" .

No geral, todos esses meios de divulgação podem vir, de fato, a colaborar para a potencialização do uso dessa ferramenta pedagógica e a facilitar a aprendizagem dos conteúdos microbiológicos.

\section{Conclusão}

O processo de elaboração de paródias pelo grupo Musicalizando a biologia representou excelente forma de trabalhar conteúdos diversos de microbiologia, abordando desde temas cotidianos como o uso indevido de antimicrobianos e o combate à epidemia da dengue até conteúdos mais estruturantes para a disciplina como as formas e morfologias das bactérias, apresentando potencial de trabalhar de forma lúdica essas temáticas não só nas escolas e demais ambientes formais da educação, como também na comunidade em geral. A paródia se apresenta como exercício pedagógico útil para demonstrar, representar e aplicar diversos conteúdos teóricos de forma lúdica e criativa, além de despertar a curiosidade e o interesse dos alunos, motivando-os a aprender, de forma mais prazerosa, conteúdos considerados abstratos. Ademais, pode também incentivá-los a expressarem seus conhecimentos, concepções e erros conceituais sobre o conteúdo trabalhado, o que pode facilitar o processo de aprendizagem.

Assim, além de ser uma ótima estratégia didática aliada ao processo de ensino, o uso de paródias também permite aos alunos moldarem suas habilidades musicais, cognitivas e afetivas, bem como estreita as relações entre eles, os professores, os tutores e a coordenação do curso, pois estimula a comunicação e permite uma maior interatividade, requisitos importantes na modalidade a distância. As paródias produzidas pelo grupo têm tido excelente aceitação por parte dos alunos e professores, principalmente por terem sido divulgadas de diversas formas, evidenciando que a escolha dos canais certos de divulgação pode vir, de fato, a colaborar para a potencialização do uso dessa ferramenta pedagógica.

Além disso, as atividades e ações realizadas junto às escolas onde elas têm sido também utilizadas têm representado momentos ricos no processo de formação desses alunos, pois proporcionam conhecimentos básicos sobre microbiologia, o que contribui para torná-los indivíduos mais conscientes sobre as questões relacionadas ao meio ambiente, à higiene pessoal e à saúde. Por fim, constata-se a utilização da paródia como uma ferramenta importante, que pode contribuir, sobremaneira, para o processo de ensino-aprendizagem de microbiologia. 


\section{Referências}

1. Santos SC. O processo de ensino-aprendizagem e a relação professor-aluno: aplicação dos "sete princípios para a boa prática na educação de Ensino Superior". Cad Pesq Adm. 2001; 8(1):69-82.

2. Pereira MGP, Romão EP, Pantoja LDM, Paixão GC. O cordel no ensino de microbiologia: a cultura popular como ferramenta pedagógica no ensino superior. Reciis 2014; 8(4):512-24.

3. Brasil. Lei 9.394 de 20 de dezembro de 1996. Estabelece as diretrizes e bases da educação nacional. Diário Oficial da União, Brasília (DF), 199623 dez.

4. Dias MAS. Dificuldades na aprendizagem dos conteúdos de Biologia: evidencias a partir das provas de múltipla escolha do vestibular da UFRN (2001-2008) [tese]. Universidade Federal do Rio Grande do Norte, Natal; 2008.

5. Prado C, Vaz, DR, Almeida DM de. Teoria da aprendizagem significativa: elaboração e avaliação de aula virtual na plataforma Moodle. R Bras Enferm. 2011;64(6):1114-21.

6. Barbosa FG, Oliveira NC de. Estratégias para o ensino de microbiologia: uma experiência com alunos do ensino fundamental em uma escola de Anápolis-GO. R Ens Educ Ci Hum. 2015; 16(1):5-13.

7. Cassanti AC, Araújo EE, Ursi S. Microbiologia democrática: estratégias de ensino aprendizagem e formação de professores [Internet]. [local desconhecido]: [editora desconhecida]. [citado em 2017 fev. 07]. Disponível em: http://botanicaonline.com.br/geral/arquivos/Cassantietal2008\%20microbiologia.pdf

8. Kimura AH, Oliveira GS, Candorieiro S, Souza PC, Schuruff PA, Medeiros LP, et al. Microbiologia para o ensino médio e técnico: contribuição da extensão ao ensino e aplicação da ciência. Revista Conexão UEPG. 2013;9(2):254-67.

9. Barbosa FH, Barbosa, LPJL. Alternativas metodológicas em microbiologia: viabilizando atividades práticas. R Biol Ci Terra. 2010;10(2):134-43.

10. Campos LML, Bortoloto TM, Felicio AKC. 2008. A produção de jogos didáticos para o ensino de ciências e biologia: uma proposta para favorecer a aprendizagem [Internet]. [local desconhecido]: [editora desconhecida]. [citado em 2017 fev. 07]. Disponível em: http://www.unesp.br/prograd/PDFNE2002/ aproducaodejogos.pdf.

11. Xavier RAG. O uso de paródias em abordagens conceituais: vivência na formação inicial para a docência [Internet]. In: Anais do Seminário Internacional de Educação Superior: formação e conhecimento; 2014 out. 26-28; Sorocaba: UNISO; 2014 [citado em 2017 02 06]. Disponível em: https://www.uniso.br/ publicacoes/anais eletronicos/2014/1 es formacao de professores/47.pdf.

12. Silveira MP, Kiouranis NMM. A música e o ensino de química. Quí Nova Esc; 2008;28(1):28-31.

13. Cabrera WB. A ludicidade para o Ensino Médio na disciplina de Biologia: contribuição ao processo de aprendizagem em conformidade com os pressupostos teóricos da aprendizagem significativa [dissertação]. Londrina: Universidade Estadual de Londrina; 2006.

14. Gomes RAG, Santos A de S, Hora BLV da, Oliveira KS, Zuza H, Costa IAS. Venha cantar com a gente! produção de paródias como estratégia didática no ensino e aprendizagem de Biologia. R SBEnBio; 2014; 7(1):6556-65.

15. Loureiro AMA. O ensino de música na escola fundamental. Campinas: Papirus; 2003.

16. Wermann NS, Mager BG, Ferraro CS, Santos FGS, Bernard FL, Gotardi J, Antoniazzi LQ. Música paródia: uma ferramenta de sucesso no ensino de Química [Internet]. In: Anais do 12 Salão de Iniciação Científica PUCRS; 2011; Porto Alegre: PUCRS; 2011 [citado em 201702 06]. Disponível em: http:// ebooks.pucrs.br/edipucrs/anais/seminarioic/20112/5/5/1/1.pdf.

17. Brasil. Secretaria da Educação Fundamental. Parâmetros curriculares nacionais: terceiro e quarto ciclos do ensino fundamental: ciências naturais. Brasília (DF): MEC, 1998.

18. Mattar J. YouTube na Educação [Internet]. [citado em 201702 07].Disponível em: http://blog. joaomattar.com/youtube-na-educacaol.

19. Schneider C, Ribeiro LOM. YouTube: parâmetros de legibilidade da produção de vídeos para a educação a distância. In: Anais do $19^{\circ}$ Congresso Internacional ABED de Educação a Distância; 2013 set. 9-12; Salvador. Bahia: ABED; 2013. 
20. Vieira ER, Silva RC. Blogs, webfolios e a educação a distância (ead): contribuições para a aprendizagem [Internet]. [citado em 201702 07]. Disponível em: http://www.abed.org.br/hotsite/20ciaed/pt/anais/pdf/273.pdf.

21. Barbosa CAP, Serrano CA. O blog como ferramenta para construção do conhecimento e aprendizagem colaborativa [Internet]. In: Anais do $12^{\circ}$ Congresso Internacional de Educação a Distância; 2005 set. 1822; Florianópolis. Santa Catarina: ABED; 2005 [citado em 0207 2017]. Disponível em: http://www.abed. org.br/congresso2005/por/pdf/011tcc3.pdf. 